\title{
PENGARUH CURRENT RATIO, DEBT TO EQUITY RATIO, DAN NET PROFIT MARGIN TERHADAP PERUBAHAN LABA PADA PERUSAHAAN MANUFAKTUR SUB SEKTOR MAKANAN DAN MINUMAN DI BEI PERIODE 2016-2019
}

\author{
Nafiya Ayu Kusumawardani ${ }^{1}$, Mohamad Zulman Hakim ${ }^{2}$, Dirvi Surya \\ Abbas $^{3}$ \\ Universitas Muhammadiyah Tangerang ${ }^{1,2,3}$ \\ Email korespondensi: nafiyakusumawardani@gmail.com
}

\begin{abstract}
Abstrak: Penelitian ini bertujuan untuk menguji adanya pengaruh variabel Independen Current Ratio (CR), Debt To Equity Ratio (DER), dan Net Profit Margin (NPM) terhadap variabel dependen yaitu perubahan laba pada perusahaan manufaktur sub sektor makanan dan minuman yang terdaftar di Bursa Efek Indonesia. Populasi penelitian ini meliputi perusahaan manufaktur sub sektor makanan dan minuman yang terdaftar di Bursa Efek Indonesia (BEI) periode 2016-2019. Teknik pengambilan sampel yang digunakan adalah dengan metode purposive sampling. Berdasarkan hasil kriteria yang telah ditentukan maka diperoleh sampel sebanyak 15 perusahaan yang terdaftar di Bursa Efek Indonesia (BEI) periode 2016-2019. Jenis data yang digunakan adalah data sekunder yang diperoleh dari Bursa Efek Indonesia. Alat analisis penelitian ini menggunakan Regresi Data Panel Penelitian ini menggunakan metode kuantitatif yang diolah menggunakan sofware E-Views 9.0. Tingkat signifikasi yang digunakan sebesar 0,05 . Sementara itu, alat uji yang digunakan untuk menguji kelayakan model regresi adalah uji asumsi klasik (normalitas, uji multikolinearitas, uji autokorelasi, dan uji heteroskedastistas) dan untuk pengujian hipotesis menggunakan koefiesien determinasi,uji-t, dan uji-f. Berdasarkan hasil analisis regresi menunjukan bahwa CR, DER, dan NPM berpengaruh secara signifikan secara bersamaan terhadap perubahan laba. Adapun CR dan DER berpengaruh positif dan signifikan terhadap perubahan laba, sedangkan NPM berpengaruh negatif dan signifikan terhadap perubahan laba.
\end{abstract}

Kata Kunci : CR, DER, NPM, Perubahan Laba

Perubahan laba adalah peningkatan dan penurunan laba yang diperoleh / dialami oleh perusahaan dibandingkan tahun sebelumnya (Putri: 2010). Variabel dependen dalam penelitian ini adalah perubahanl aba yang merupakan hasil dari perbandingan laba periode tertentu dengan laba sebelumnya.Peningkatan maupun penurunan laba merupakan perubahan laba.Perubahan laba yang tinggi berarti laba yang diperoleh oleh perusahaan semakin tinggi. Perubahan laba akan mempengaruhi keputusan investasi yang dilakukan oleh para investor (Nurmalasari: 2012).

Pada dasarnya, suatu perusahaan didirikan dengan tujuan agar perusahaan tersebut dapat berkembang serta mampu menjaga dan mempertahankan kelangsungan usahanya di masa mendatang. Salah satu manfaat laba adalah untuk memprediksi peruahan laba perusahaan di tahun yang akan datang. Perubahan laba merupakan kenaikan laba atau penurunan laba per tahun. Penilaian tingkat keuntungan investasi oleh investor didasarkan oleh kinerja keuangan perusahaan laba dari tahun ke tahun. Para investor dalam menilai perusahaan tidak hanya 
melihat laba dalam satu periode melainkan terus memantau perubahan laba dari tahun ke tahun (Lusiana, 2008).

Beberapa penelitian tentang analisis rasio keuangan dalam memprediksi perubahan laba telah beberapa kali dilakukan di Indonesia antara lain oleh Ugeng Budi Haryoko dan Amalia Syahida (2019) yang melakukan penelitian mengenai pengaruh Current Ratio (Rasio Lancar) dan Debt To Assets Ratio (Rasio Utang) Terhadap Perubahan Laba pada PT Astra Agro Lestari periode 2012-2016 dengan menggunakan model regresi linear berganda. Hasil penelitian mereka menunjukkan bahwa Current Ratio dan Debt To Assets Ratio secara bersama-sama tidak memiliki pengaruh yang signifikan dan simultan terhadap perubaha laba. Dalam penelitian yang dilakukan oleh Dina Rohmatin (2017) tentang pengaruh Debt To Equity Ratio (DER), Total Assets Turnover (TATO), Gross Profit Margin (GPM), Return On Equity (ROE) terhadap perubahan laba pada perusahaan property dan real estate yang listing di Bursa Efek Indonesia tahun 2013- 2015 dengan menggunakan pendekatan kuantitatif dengan metode expost facto. Hasil penelitian yang diperoleh menunjukkan bahwa Debt To Equity ratio (DER), Total assets turnover (TATO), Gross Profit Margin (GPM) dan Return On Equity (ROE) secara simultan memiliki pengaruh yang signifikan terhadap perubahan laba. Debt To Equity ratio (DER) itu sendiri dalam penelitian ini berpengaruh negatif terhadap pengungkapan perubahan laba. Pada penelitian yang dilakukan oleh Fidyah Arini Kusuma (2019) tentang Pengaruh rasio-rasio keuangan terhadap perubahan laba dan cash flow pada perusahaan manufaktur yang terdaftar di Bursa Efek Indonesia pada tahun 2014- 2016 dengan menggunakan metode purposive sampling. Hasil penelitian menunjukkan bahwa Current ratio, Total assets Turnover, Return On Equity, dan Net Profit Margin tidak berpengaruh signifikan terhadap perubahan laba.

Fenomena yang terjadi pada PT.Kino mengalami penurunan volume penjualan mencapai $27 \%$ pada semester $1 / 2017$ dibandingan dengan periode tahun lalu yang dipengaruhi oleh penyusutan permintaan segmen beverages karena daya beli masyarakat belum stabil. . PT Kino Indonesia Tbk. (Kino) mencatat kontribusi setiap segmen kepada penjualan total perusahaan, yakni personal care mencapai 50\%, beverage 35\% Food And Confectionaries $14 \%$ serta pharmaceutical 1\%. Segmen pharmaceutical dimaklumi oleh PT Kino Indonesia Tbk. (Kino) jika kontribusinya sangat kecil dikarenakan divisi tersebut baru dibentuk. penurunan tren penjualan dari berbagai produk minuman dalam kemasan ikut mempengaruhi segmen Food \& Confectionaries yang didominasi $80 \%$ oleh minuman berjenis serbuk. Industri makanan dan minuman mencatatkan pertumbuhan sebanyak $7,19 \%$ pada kuartal II/2017. Pencapaian ini berkontribusi terhadap produk domestik bruto (PDB) industri nonmigas sebesar $34,17 \%$.

\section{Pengaruh Current Ratio (CR) Terhadap Perubahan Laba}

Current Ratio (CR) merupakan rasio yang mengukur kinerja 
keuangan neraca likuiditas perusahaan.Rasio lancar ini menunjukkan kemampuan perusahaan untuk memenuhi kewajiban hutang jangka pendeknya dalam periode 1 tahun. Perusahaan yang dapat melunasi kewajiban jangka pendek dapat dikategorikan perusahaan yang likuid sedangkan yang tidak likuid itu disebut ilikuid. Menurut (Sutrisno, 2009 : 216) Current ratio adalah rasio yang bertujuan untuk memperlihatkan perbedaan antara aset lancar yang perusahaan miliki dengan liabilitas jangka pendeknya. Aset lancar ini terdiri atas piutang dagang, kas, persediaan barang dagang, dan aset lancar lainnya. Sedangkan utang jangka pendek meliputi utang dagang, utang wesel, utang bank, utang gaji dan utang lainnya yang segera harus dibayar. Current Ratio diformulasikan dengan menggunakan rumus :

$$
\frac{\text { Aset Lancar (Current } \text { Assets) }}{\mathbf{H}_{\mathbf{1}} \text { : Current ratio }(C R) \text { berpengaruh positif terhadap perubahan laba }}
$$

\section{Pengaruh Debt To Equity Ratio (DER) Terhadap Perubahan Laba}

Debt to Equity Ratio (DER) adalah rasio hutang terhadap ekuitas.Bisa juga disebutdengan rasio utang modal. Arti Debt to Equity Ratio (DER) merupakan sebuah rasio keuangan yang memiliki tujuan untuk melihat perbandingan antara total utang dan ekuitas. Jumlah yang proporsional yaitu menunjukkan jumlah utang dan ekuitas yang digunakan sebagai operasional perusahaan Debt to Equity Ratio (DER) adalah rasio keuangan yang utama dalam suatu perusahaan. Untuk mengukur sejauh mana utang dapat ditutupi oleh aset.Semakin kecil rasio maka semakin aman, utang ke aset harus lebih kecil. Debt To Equity Ratio (DER) dapat diformulasikan dengan rumus :

\section{Total Utang (Debt Total)}

\section{$\overline{\text { Total Ekuitas (Equity Total) }}$}

$\mathbf{H}_{2}$ : Debt To Equity Ratio (DER) berpengaruh positif terhadap perubahan laba

\section{Pengaruh Net Profit Margin (NPM) Terhadap Perubahan Laba}

Net Profit Margin (NPM) Menurut (Wulansari 2013:4) merupakan perbandingan antara laba bersih setelah pajak (yaitu laba sebelum pajak penghasilan dikurangi dengan pajak penghasilan) terhadap penjualan bersih (net sales). Semakin tinggi net profit margin, maka semakin baik operasi suatu perusahaan, dapat dikatakan baik tergantung dari jenis industrinya. Net Profit Margin (NPM) dapat diformulasikan dengan rumus :

\section{Laba Bersih Setelah Pajak}

\section{Penjualan Bersih}

$\mathbf{H}_{3}$ : Net Profit Margin (NPM) berpengaruh positif terhadap perubahan laba

\section{METODE \\ Pendekatan Penelitian}


Populasi dan sampel metode penelitian ini adalah klausal atau dengan kata lain penelitian yang memiliki tujuan untuk menguji hubungan ataupun pengaruh antara satu variabel terhadap variabel lainnya. Populasi dalam penelitian ini adalah perusahaan manufaktur sub sektor makanan dan minuman yang terdaftar di Bursa Efek Indonesia (BEI) tahun 2016-2019.

\section{Metode Pengambilan Sampel}

Dalam penelitian ini menggunakan Purposive Sampling untuk pengambilan sampelnya. Dimana purposive sampling ini merupakan teknik penentuan sampel dengan menggunakan pertimbangan tertentu (Sugiyono, 2012 : 96). Berdasarkan metode yang digunakan, maka terdapat kriteria yang digunakan dalam pengambilan sampel, yaitu sebagai berikut :

- Perusahaan manufaktur sub sektor makanan dan minuman yang terdaftar di Bursa Efek Indonesia yang menyediakan laporan keuangan selama periode penelitian tahun 20162019.

- Perusahaan manufaktur sub sektor makanan dan minuman yang menerbitkan laporan keuangan selama kurun waktu periode penelitian tahun 2016-2019 dan diterbitkan pada akhir tahun.

- Perusahaan manufaktur sub sektor makanan dan minuman yang selama periode penelitian tahun 2016-2019 penerbitan laporan keuangannya menggunakan mata uang Rupiah.

- Perusahaan manufaktur sub sektor makanan dan minuman yang selama periode penelitian tahun 2016-2019 mengalami perubahan laba/rugi tahun berjalan secara fluktuatif.

\section{A. Metode Analisis Data}

1. Analisis Statistik Deskriptif

Analisis ini bertujuan untuk memberikan gambaran atau mendeskripsikan data dalam variabel yang dilihat dari nilai ratarata (mean), minimum, maximum, dan standar deviasi. Analisis statistik deskriptif ini digunakan dalam menganalisis data dengan cara mendeskripsikan atau menggambarkan data yang telah terkumpul agar menjadi informasi yang lebih jelas serta mudah dipahami dalam memberikan gambaran mengenai penelitian berupa hubungan dari masing-masing variabel.

\section{Estimasi Model Regresi Data Panel}

a) Common Effect Model (CEM)

Common Effect Model (CEM) adalah pendekatan model data panel yang paling sederhana karena hanya mengkombinasikan data time series dan cross section. Pada model ini tidak diperhatikan dimensi waktu maupun individu, 
sehingga diasumsikan bahwa perilaku data perusahaan sama dalam berbagai kurun waktu.

b) Fixed Effect Model (FEM)

Fixed Effect Model (FEM) mengansumsikan bahwa perbedaan antar individu dapat diakomodasi dari perbedaan intersepnya. Untuk mengestimasi data panel Fixed Effect Model (FEM) menggunakan teknik variable dummy untuk menangkap perbedaan intersep antar perusahaan, perbedaan intersep bisa terjadi karena perbedaan budaya kerja, manajerial, dan insentif.

c) Random Effect Model (REM)

Random Effect Model (REM) mengestimasi data panel dimana variabel gangguan mungkin saling berhubungan antar waktu dan antar individu. Pada Random Effect Model (REM) perbedaan intersep diakomodasi oleh error terms masing-masing perusahaan. Keuntungan menggunakan model Random Effect yakni menghilangkan heteroskedastisitas.

\section{Teknik Pemilihan Model Regresi Data Panel}

a) Uji Chow

Uji Chow adalah pengujian untuk menentukan model apakah Common Effect Model (CEM) atau Fixed Effect Model (FEM) yang lebih tepat digunakan dalam mengestimasi data panel.

$\mathrm{H}_{0}$ : Model mengikuti Common Effect Model (CEM), jika probabilitas Cross-section F dan Cross-section Chi-square > a $(0,05)$

$\mathbf{H}_{\mathrm{a}}$ : Model mengikut Fixed Effect Model (FEM), jika probabilitas Cross-section $\mathrm{F}$ dan Cross-section Chi-square $<\alpha$ (0,05Cross-section F dan Cross-section Chi-squar.

b) Uji Hausman

Uji Hausman adalah pengujian statistik untuk memilih apakah Fixed Effect Model (FEM) ataukah Random Effect Model (FEM) yang paling tepat digunakan.Cross-section Random (Eksandy, 2018) dengan hipotesis sebagai berikut:

$\mathbf{H}_{0}$ : Jika nilai Probabilitas (Prob). Cross-section Random $>\alpha$ (0.05).

$\mathbf{H}_{\mathrm{a}}$ : Jika nilai Probabilitas (Prob).Cross-section Random $<\alpha$ (0.05).

c) Uji Lagrange Multiplier

Uji Lagrange Multiplier digunakan untuk mengetahui apakah Common Effect Model (CEM) atau Random Effect Model (REM) yang lebih tepat digunakan.

$\mathbf{H}_{0}$ : Jika nilai prob Cross-section Breusch-Pagan> a (0.05).

$\mathbf{H}_{\mathbf{a}}$ : Jika nilai prob Cross-section Breusch-Pagan < $\alpha(0.05)$. 


\section{Uji Hipotesis}

a) Uji Kelayakan Model (Uji F)

Apabila Uji F tidak berpengaruh maka penelitian tidak layak untuk dilanjutkan karena model penelitian tidak mampu menjelaskan adanya hubungan antara variabel independen dengan dependen. Bisa juga hal ini terjadi karena adanya hubungan antar variabel independen (Multikolinearitas) sehingga menyebabkan model penelitian tidak fit (Eksandy, 2018).

1) Berdasarkan perbandingan F-statistik dengan tabel dengan $\mathrm{F}$ tabel :

$\mathbf{H}_{0}$ : Jika F-statistic < $\mathrm{F}$ Tabel, maka $\mathrm{H}_{0}$ diterima.

$\mathbf{H}_{\mathrm{a}}$ : Jika F-statistic> $\mathrm{F}$ Tabel, maka $\mathrm{H}_{\mathrm{a}}$ diterima

1) Berdasarkan probabilitas

$\mathbf{H}_{0}$ : Jika nilai Prob. (F-statistic) $>\alpha(0,05)$, maka $\mathrm{H}_{0}$ diterima

$\mathbf{H}_{\mathbf{a}}$ : Jika nilai Prob. (F-statistic) $<\alpha(0,05)$, maka $\mathrm{H}_{\mathrm{a}}$ diterima

b) Koefisien Determinasi

Hasil Koefisien Determinasi menjelaskan seberapa jauh kemampuan model regresi dalam menerangkan variasi variabel bebas mempengaruhi variabel terikat.

Nilai Adjusted $R$-squared berada antara 0 sampai 1 dengan penjelasan sebagai berikut:

1) Nilai Adjusted $R$-squared harus berkisar 0 sampai 1. Jika nilai Adjusted $R$-squared sama dengan 1, berarti naik atau turunnya variabel dependen $(Y)$ 100\% dipengaruhi oleh variabel independen $(\mathrm{X})$.

2) Jika nilai Adjusted $R$-squared sama dengan 0 , berarti tidak ada hubungan sama sekali antara variabel independen terhadap variabel dependen.

c) Uji t

Uji t menjelaskan signifikansi pengaruh variabel bebas secara parsial terhadap variabel terikat. Hipotesis dalam uji t adalah sebagai berikut:

1) Berdasarkan perbandingan $t$-statistic dengan t tabel :

$\mathrm{H}_{0}$ : Jika nilai $t$-statistic $<\mathrm{t}$ tabel, maka $\mathrm{H}_{0}$ diterima

$\mathrm{H}_{\mathrm{a}}$ : Jika nilai $t$-statistic $>\mathrm{t}$ tabel, maka $\mathrm{H}_{\mathrm{a}}$ diterima

2) Berdasarkan probabilitas

$\mathrm{H}_{0}$ : Jika nilai Prob. $>\alpha(0,05)$, maka $\mathrm{H}_{0}$ diterima.

Ha: Jika nilai Prob. < $\alpha(0,05)$, maka Ha diterima

\section{Analisis Regresi Data Panel}

Analisis regresi data panel merupakan gabungan antara data cross-section dan data time series, dimana unit cross-section yang sama diukur di waktu yang berbeda. Persamaan regresi data panel adalahh sebagai berikut : 
Perubahan Laba $=$

$$
\Delta Y_{t}=\frac{Y_{t}-Y_{t-1}}{Y_{t-1}} x 100
$$

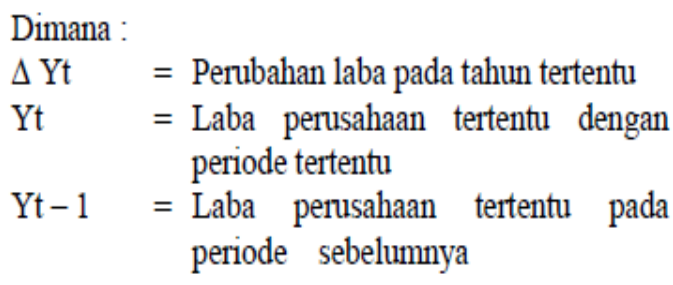

\section{HASIL}

Tabel 1. Analisis Statistik Deskriptif

\begin{tabular}{|c|c|c|c|c|}
\hline & PL & CR & DER & NPM \\
\hline Mean & -0.143487 & 2.842020 & 0.695972 & 0.137750 \\
\hline Median & 0.154500 & 1.672150 & 0.593750 & 0.073900 \\
\hline Maximum & 1.371600 & 15.82230 & 1.898200 & 4.260600 \\
\hline Minimum & -10.18750 & 0.088400 & -2.127300 & -0.846800 \\
\hline Std. Dev. & 1.664652 & 3.083718 & 0.731622 & 0.583529 \\
\hline Skewness & -4.773156 & 2.323670 & -1.099969 & 5.915884 \\
\hline Kurtosis & 26.99933 & 8.563569 & 6.064426 & 43.17474 \\
\hline & & & & \\
\hline Jarque-Bera & 1667.750 & 131.3777 & 35.57608 & 4385.001 \\
\hline Probability & 0.000000 & 0.000000 & 0.000000 & 0.000000 \\
\hline & & & & \\
\hline Sum & -8.609200 & 170.5212 & 41.75830 & 8.265000 \\
\hline Sum Sq. Dev. & 163.4930 & 561.0497 & 31.58100 & 20.08983 \\
\hline Observations & 60 & 60 & 60 & 60 \\
\hline
\end{tabular}

Berdasarkan tabel 1, Nilai Mean terbesar dialami oleh variabel CR yaitu sebesar 2.842020 sementara variabel Perubahan Laba memiliki nilai Mean terkecil yaitu sebesar -0.143487 . Nilai Median terbesar dialami oleh variabel CR yaitu sebesar 1.672150 sementara variabel NPM memiliki nilai Median terkecil yaitu sebesar 0.073900. Nilai Maximum terbesar dialami oleh variabel CR yaitu sebesar 15.82230 sementara variabel PL memiliki nilai Maximum terkecil yaitu sebesar 1.371600. Nilai Minimum terbesar dialami oleh variabel CR yaitu sebesar 0.088400 sementara variabel PL memiliki nilai Minimum terkecil yaitu sebesar -10.18750. Nilai Standar Deviasi terbesar dialami oleh variabel CR yaitu sebesar 3.083718 yang berarti bahwa variabel bahwa variabel CR memiliki tingkat risiko yang lebih tinggi mengalami perubahan dibandingkan dengan variabelvariabel yang lain selama periode penelitian. Sementara variabel NPM mempunyai tingkat risiko yang paling rendah, yaitu sebesar 0.583529 . Hal ini menunjukkan bahwa variabel $c$ selama periode penelitian mengalami perubahan yang tidak terlalu fluktuatif. Nilai Skewness yang memiliki nilai di atas 0 (nol) yaitu variabel CR dan NPM yang berarti bahwa asimetri 
distribusi data di sekitar mean tidak normal, sedangkan variabel PL dan DER memiliki nilai di bawah 0 (nol) yang berarti bahwa asimetri distribusi data di sekitar mean bersifat normal. Nilai Kurtosis untuk variabel PL, CR, DER, dan NPM memiliki nilai Kurtosis lebih dari 3 yang berarti bahwa ketinggian distribusi data tidak normal, sementara jika variabel memiliki nilai kurtosis kurang dari 3 yang berarti bahwa ketinggian distribusi data bersifat normal. Jarque-Bera adalah uji statistik untuk mengetahui apakah data berdistribusi normal. Uji ini mengukur perbedaan skewness dan kurtosis data dan dibandingkan dengan apabila data nya bersifat normal. Dengan $H_{0}$ pada data berdistribusi normal, uji Jarque-Bera didistribusi dengan $x^{2}$ dengan derajat bebas (degree of freedom) sebesar 2.Probability menunjukkan kemungkinan nilai Jarque-Bera melebihi (dalam nilai absolut) nilai terobservasi di bawah hipotesis nol. Nilai probabilitas yang kecil cenderung mengarahkan pada penolakan hipotesis nol distribusi normal.

Tabel 2. Uji Chow

\begin{tabular}{lllrl|}
\hline $\begin{array}{l}\text { Redundant Fixed Effects Tests } \\
\text { Equation: EQ01 } \\
\text { Test cross-section fixed effects }\end{array}$ & & & \\
\hline \hline Effects Test & Statistic & d.f. & Prob. \\
\hline \hline Cross-section F & 1.966702 & $(14,42)$ & 0.0460 \\
Cross-section Chi-square & 30.248623 & 14 & 0.0071 \\
\hline \hline
\end{tabular}

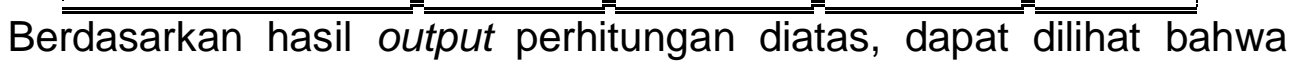
nilai Probabilitas Cross-section F adalah 0.0460 dan Cross-section Chisquare $>\alpha(0.05)$, maka dapat disimpulkan bahwa Common Effect Model (CEM) lebih layak digunakan di banding Fixed Effect Model (FEM)).

Tabel 3. Uji Hausman

\begin{tabular}{|c|c|c|c|}
\hline \multicolumn{4}{|c|}{$\begin{array}{l}\text { Correlated Random Effects - Hausman Test } \\
\text { Equation: EQ01 } \\
\text { Test cross-section random effects }\end{array}$} \\
\hline Test Summary & $\begin{array}{l}\text { Chi-Sq. } \\
\text { Statistic }\end{array}$ & Chi-Sq. d.f. & Prob. \\
\hline Cross-section random & 0.920771 & 3 & 0.8204 \\
\hline
\end{tabular}

Berdasarkan hasil output perhitungan diatas dapat dilihat bahwa nilai Probabilitas Cross-section random adalah $0.8204>$ a (0.05), maka dapat disimpulkan bahwa Random Effect Model (REM) lebih layak digunakan dibandingkan dengan Fixed Effect Model (FEM).

Tabel 4. Uji Lagrange Multiplier

Lagrange Multiplier Tests for Random Effects

Null hypotheses: No effects

Alternative hypotheses: Two-sided (Breusch-Pagan) and one-sided 
(all others) alternatives

\begin{tabular}{|lccc|}
\hline \hline & \multicolumn{3}{c|}{ Test Hypothesis } \\
& Cross-section & Time & Both \\
\hline \hline Breusch-Pagan & $\begin{array}{l}3.016017 \\
(0.0824)\end{array}$ & $\begin{array}{l}0.416635 \\
(0.5186)\end{array}$ & $\begin{array}{l}3.432652 \\
(0.0639)\end{array}$ \\
\hline
\end{tabular}

Berdasarkan hasil output perhitungan diatas dapat dilihat bahwa nilai Probabilitas Cross section random adalah $0.8204>\alpha(0.05)$, maka dapat disimpulkan bahwa Common Effect Model (CEM) lebih layak digunakan dibandingkan dengan Random Effect Model (REM).

Tabel 5. Kesimpulan Model Regresi

\begin{tabular}{|c|l|c|c|}
\hline No & \multicolumn{1}{|c|}{ Metode } & Pengujian & Hasil \\
\hline 1 & Uji Chow & CEM vs FEM & CEM \\
\hline 2 & Uji Hausman & REM vs FEM & REM \\
\hline 3 & Uji Lagrange Multiplier & CEM vs REM & CEM \\
\hline
\end{tabular}

Berdasarkan hasil ketiga pengujian tersebut, maka dapat disimpulkan bahwa model regresi data panel yang akan digunakan dalam uji hipotesis dan persamaan regresi data panel adalah Common Effect Model (CEM).

Tabel 6. Uji Kelayakan Model (Uji F)

\begin{tabular}{|lrlr|}
\hline R-squared & 0.556863 & Mean dependent var & -0.143487 \\
Adjusted R-squared & 0.533124 & S.D. dependent var & 1.664652 \\
S.E. of regression & 1.137429 & Akaike info criterion & 3.159759 \\
Sum squared resid & 72.44972 & Schwarz criterion & 3.299382 \\
Log likelihood & -90.79276 & Hannan-Quinn criter. & 3.214373 \\
F-statistic & 23.45729 & Durbin-Watson stat & 1.979105 \\
Prob(F-statistic) & 0.000000 & & \\
\hline
\end{tabular}

Nilai F-statistic sebesar 23.96365 dengan nilai Prob. (F-statistic) sebesar 0.000000 . Sementara F Tabel dengan tingkatan $\alpha=5 \%$, df1 (k-1) $=4-1=3$ dan df2 $(\mathrm{n}-\mathrm{k})=60-4=56$ didapat nilai $\mathrm{F}$ Tabel sebesar 2.77. Dengan demikian F-statistic(23.45729) > F Tabel (2.77) dan nilai Prob. (Fstatistic) $0.000000<0.05$ maka dapat disimpulkan bahwa $\mathrm{H}_{\mathrm{a}}$ diterima, maka dengan demikian dapat disimpulkan pula bahwa variabel-variabel independen dalam penelitian ini yang terdiri dari Current Ratio (CR), Debt To Equity Ratio(DER), dan Net Profit Margin (NPM)secara simultan memiliki pengaruh terhadap Perubahan Laba.

Tabel 7. Koefisien Determinasi

\begin{tabular}{lrlr|}
\hline R-squared & 0.556863 & Mean dependent var & -0.143487 \\
Adjusted R-squared & 0.533124 & S.D. dependent var & 1.664652 \\
S.E. of regression & 1.137429 & Akaike info criterion & 3.159759 \\
Sum squared resid & 72.44972 & Schwarz criterion & 3.299382 \\
Log likelihood & -90.79276 & Hannan-Quinn criter. & 3.214373 \\
\hline F-statistic & 23.45729 & Durbin-Watson stat & 1.979105 \\
Prob(F-statistic) & 0.000000 & & \\
\hline \hline
\end{tabular}


Nilai Adjusted $R$-squared sebesar 0.533124, artinya bahwa kemampuan variabel independen secara simultan (Current Ratio, Debt To Equity Ratio, dan Net Profit Margin) dalam menjelaskan variabel dependen Perubahan Laba yang mendekati 1 berarti variabel-variabel independen dalam model regresi semakin besar kemampuannya dalam menjelaskan variabel dependen.

Tabel 8. Uji t

\begin{tabular}{|c|c|c|c|c|}
\hline \multicolumn{5}{|c|}{$\begin{array}{l}\text { Dependent Variable: PL } \\
\text { Method: Panel Least Squares } \\
\text { Date: } 11 / 08 / 20 \text { Time: } 20: 17 \\
\text { Sample: } 20162019 \\
\text { Periods included: } 4 \\
\text { Cross-sections included: } 15 \\
\text { Total panel (balanced) observations: } 60\end{array}$} \\
\hline Variable & Coefficient & Std. Error & t-Statistic & Prob. \\
\hline $\mathrm{C}$ & -1.075099 & 0.277330 & -3.876607 & 0.0003 \\
\hline CR & 0.144667 & 0.050681 & 2.854470 & 0.0060 \\
\hline DER & 1.061639 & 0.213028 & 4.983577 & 0.0000 \\
\hline NPM & -1.585519 & 0.259694 & -6.105338 & 0.0000 \\
\hline
\end{tabular}

Nilai $t$-statistic Current Ratio (CR) sebesar 2.854470, sementara $\mathrm{t}$ Tabel dengan tingkat $\alpha=5 \%$, df $(n-k)=56$ didapat nilai t Tabel sebesar 2.00324 Dengan demikian t-statistic Current Ratio (CR) (2.854470) $>\mathrm{t}$ Tabel (2.00324) dan nilai Prob. $0.0060<0.05$. Maka dapat disimpulkan bahwa variabel Current Ratio $(C R)$ dalam penelitian ini berpengaruh terhadap pengungkapan Perubahan Laba.

Nilai $t$-statistic Debt To Equity Ratio (DER) sebesar 4.983577, sementara $\mathrm{t}$ Tabel dengan tingkat $\alpha=5 \%$, df $(\mathrm{n}-\mathrm{k})=56$ didapat nilai $\mathrm{t}$ Tabel sebesar 2.00324. Dengan demikian t-statistic Debt To Equity Ratio (DER) (4.983577) > t Tabel (2.00324) dan nilai Prob. $0.0000<0.05$. Maka dapat disimpulkan bahwa variabel Debt To Equity Ratio (DER) dalam penelitian ini berpengaruh terhadap pengungkapan Perubahan Laba.

Nilai $t$ - statistic Net Profit Margin (NPM) sebesar 6.105338, sementara t Tabel dengan tingkat $\alpha=5 \%$, df $(n-k)=56$ didapat nilai t Tabel sebesar 2.00324. Dengan demikian t- statistic Net Profit Margin (NPM) (6.105338) > t Tabel (2.00324) dan nilai Prob. $0.0000<0.05$. Maka dapat disimpulkan bahwa variabel Net Profit Margin (NPM) dalam penelitian ini terhadap perubahan laba.

\section{PEMBAHASAN}

Nilai Konstanta sebesar -1.075099 menunjukkan bahwa jika variabel independen tidak ada atau memiliki nilai 0 maka nilai pada perubahan laba sebesar - 1.075099 .

Nilai Koefisien Regresi Current ratio (CR) sebesar 0.144667 menunjukkan bahwa setiap kenaikan Current Ratio (CR) 1\% akan menyebabkan kenaikan pada perubahan laba sebesar 0.144667 . 
Nilai Koefisien Regresi Debt To Equity Ratio (DER) sebesar 1.061639 menunjukkan bahwa setiap kenaikan Debt To Equity Ratio (DER) $1 \%$ akan menyebabkan kenaikan pada perubahan laba sebesar 1.061639 .

Nilai Koefisien Regresi Net Profit Margin (NPM) sebesar -1.585519 menunjukkan bahwa setiap kenaikan Net Profit Margin (NPM) 1\% akan menyebabkan kenaikan pada perubahan laba sebesar -1.585519.

\section{Interpretasi Hasil}

Current Ratio (CR) dengan nilai koefisien 0.144667 dan nilai Prob. $0.0060<\alpha$ menunjukkan bahwa $\mathrm{H}_{1}$ diterima, maka dapat disimpulkan bahwa Current Ratio (CR) berpengaruh secara positif dan signifikan terhadap perubahan laba. Hal ini memiliki sedikit perbedaan dengan penelitian yang dilakukan oleh Chyntia Sirila Manurung dan Evelin R.R. Silalahi (2016) yang menyatakan bahwa Current Ratio (CR) berpengaruh positif tetapi tidak signifikan.

Debt To Equity Ratio (DER) dengan nilai koefisien 1.061639 dan nilai Prob $0.0000<\alpha$ menunjukkan bahwa $\mathrm{H}_{2}$ diterima, maka dapat disimpulkan bahwa Debt To Equity Ratio (DER) berpengaruh secara positif dan signifikan terhadap perubahan laba. Hal ini sesuai dengan hasil penelitian yang dilakukan oleh Fidyah Arini Kusuma W. yaitu menyatakan bahwa Debt To Equity Ratio (DER) yaitu berpengaruh signifikan terhadap perubahan laba.

Net Profit Margin (NPM) -1.585519 dan nilai Prob $0.0000<\alpha \mathrm{H}_{3}$ diterima, maka dapat disimpulkan bahwa Net Profit Margin (NPM) berpengaruh positif dan signifikan terhadap perubahan laba. Hal ini sesuai dengan hasil penelitian yang dilakukan oleh Chyntia Sirila Manurung dan Evelin R.R. Silalahi (2016) yang menyatakan bahwa Net Profit Margin (NPM) berpengaruh positif dan signifikan.

\section{KESIMPULAN}

Secara simultan (Uji F), variabel Current Ratio (CR), Debt To Equity Ratio (DER), dan Net Profit Margin (NPM) secara bersama-sama memiliki pengaruh terhadap perubahan laba. Secara parsial (Uji t), variabel Current Ratio (CR), Debt To Equity Ratio (DER), dan Net Profit Margin (NPM) secara bersama-sama memiliki pengaruh terhadap perubahan laba.

\section{Saran}

Bagi pemakai / pengguna laporan keuangan maupun pihak internal perusahaan yang akan mengambil keputusan hendaknya memperhatikan seksama laporan keuangan, terutama pada bagian Rasio Lancar, Rasio Solvabilitas, dan Rasio Profitabilitas. Pihak pengguna informasi jangan hanya menggantungkan pada laporan keuangan, tetapi harus memperhatikan juga faktor-faktor eksternal perusahaan lainnya. Bagi peneliti selanjutnya hendaknya untuk mengembangkan hipotesis penelitian agar memiliki cakupan informasi yang lebih luas bagi pengguna informasinya. Selain itu peneliti selanjutnya diharapkan menggunakan sektor yang lain yang terdapat di BEI agar informasi lebih lengkap, 
kemudian peneliti selanjutnya juga diharapkan menggunakan Rasio Aktivitas ataupun Rasio Investasi.

\section{DAFTAR PUSTAKA}

Eksandy, A. (2018). METODE PENELITIAN AKUNTANSI DAN MANAJEMEN (M. Z. Hakim (ed.)). FEB UMT. BUKU

Silviana, R. N. F. A. (2016). Pengaruh Pertumbuhan Penjualan, Profitabilitas, Dan Kebijakan Dividen Terhadap Perubahan Laba. Jurnal IImu Dan Riset Akuntansi.

Pangkong, C. M., Lambey, L., \&Afandi, D. (2017). Dampak Rasio Aktivitas Dan Rasio Likuiditas Terhadap Perubahan Laba Berbasis Fair Value (Studi Empiris Pada Perusahaan Sub Sektor Property Dan Real Estate Yang Terdaftar Di Bursa Efek Indonesia). Jurnal EMBA.

Teguh Prasetyo, E., \&Rizqi, E. (2019). Analisis Pengaruh Current Ratio (CR) dan Net Profit Margin (NPM) Terhadap Perubahan Laba Pada PT. Global Mediacom, Tbk. Jurnal IImiah Akuntansi Dan Manajemen (JIAM).

Wardhani, F. A. K. (2019). Pengaruh Rasio-Rasio Keuangan Terhadap Perubahan Laba dan Cash Flow Pada Perusahaan Manufaktur Yang Terdaftar Di Bursa Efek Indonesia Pada Tahun 2014-2016. JURNAL AKUNTANSI. https://doi.org/10.30736/jpensi.v4i1.219

Budi Haryoko, U. (2020). Pengaruh Current Ratio (Rasio Lancar) dan Debt To Total Assets Ratio (Rasio Utang) Terhadap Perubahan Laba (Keuntungan) Pada PT. Astra Agro Lestari, Tbk Periode 2012-2016. KREATIF: Jurnal Ilmiah Prodi Manajemen Universitas Pamulang. https://doi.org/10.32493/jk.v7i2.y2019.p92-103

Natalia, E. Y. (2017). Analisis Faktor Yang Mempengaruhi Perubahan Laba Perusahaan Perbankan Yang Terdaftar di BEI. Jurnal EMA. https://doi.org/10.47335/ema.v2i1.11.

Manurung, C. S., \& Silalahi, E. R. R. (2016). Analisis Rasio Keuangan Dalam Memprediksi PerubahanLaba Pada Perusahaan Manufaktur Yang Terdaftar Di Bursa Efek Indonesia (BEI). Jrak.

Vargo Christian L, T. (2018). Pengaruh Struktur Modal Dan Perputaran Persediaan Terhadap Perubahan Laba Pada Perusahaan Sub Sektor Perdagangan Eceran Di Bursa Efek Indonesia. Jurnal Akuntansi Barelang.

Catur Setia Nugraha. (2017). Analisis Pengaruh Debt To Equity Ratio (DER), Total Assets Turnover (TATO), dan Net Profit Margin (NPM) Terhadap Perubahan Laba Pada Perusahaan Manufaktur Sektor Barang Konsumsi Yang Terdaftar di Bursa Efek Indonesia Pada Periode 2013-2015. Artikel Skripsi.

Amalia Nur, C., \& Daniel Kartika, A. (2017). Pengaruh Total Asset Turnover (TATO), Return On Asset (ROA), Dan Net Profit Margin (NPM) Terhadap Perubahan Laba Pada Perusahaan Sektor Otomotif Yang Listed Di Bursa Efek Indonesia (BEI) Tahun 2012-2015. Jurnal STIE Semarang. 
Dina Rohmatin. (2017). Pengaruh Debt To Equity Ratio (DER), Total Asset Turnover (TATO), Gross Profit Margin (GPM), Return On Equity (ROE) Terhadap Perubahan Laba Pada Perusahaan Property dan Real Estate Yang Listing di Bursa Efek Indonesia Tahun 2013-2015. Artikel Skripsi. Simki-Economic.

Bursa Efek Indonesia. (n.d). https://doi.org/www.idx.co.id 